UNIVERSITE DE LAUSANNE - FACULTE DE BIOLOGIE ET DE MEDECINE

Département des Services de Chirurgie et d'Anesthésiologie

Service de Chirurgie Thoracique et Vasculaire

\title{
Value of positron emission tomography in full-thickmess chest wall resections for malignancies
}

\author{
THESE
}

préparée sous la direction du Professeur Hans-Beat Ris avec la co-direction du Docteur John O. Prior, Privat-Docent et Maître d'Enseignement et de Recherche et présentée à la Faculté de biologie et de médecine de l'Université de Lausanne pour l'obtention du grade de

DOCTEUR EN MEDECINE

par

David PETERMANN

Médecin diplômé de la Confédération Suisse

Originaire de Lignerolle (Vaud)

Lausanne

2009 


\title{
Imprimatur
}

Vu le rapport présenté par le jury d'examen, composé de

\author{
Directeur de thèse Monsieur le Professeur Hans-Beat Ris \\ Co-Directeur de thèse Monsieur le Docteur John Prior \\ Expert \\ Monsieur le Professeur honoraire Philippe Leuenberger \\ Directrice de l'Ecole Madame le Professeur Stephanie Clarke \\ doctorale
}

la Commission MD de l'Ecole doctorale autorise l'impression de la thèse de

\section{Monsieur David Petermann}

intitulée

Value of positron emission tomography in full-thickness chest wall resections for malignancies

Lausanne, le 27 octobre 2009

pour Le Doyen

de la Faculté de Biologie et de Médecine

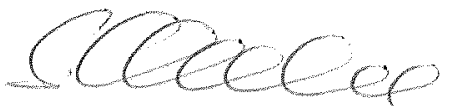

Madame le Professeur Stephanie Clarke Directrice de l'Ecole doctorale 
Rapport de synthèse

\section{Valeur de la tomographie par émission de positons pour la résection de la paroi thoracique pour des tumeurs}

Les tumeurs de la paroi thoracique sont des pathologies graves dont le traitement principal consiste en une résection chirurgicale. L'enjeu majeur de cette intervention oncologique est de réséquer la totalité de la tumeur, ce qui nécessite une planification préopératoire minutieuse. Classiquement, l'identification et la localisation de la tumeur se fait à l'aide de la tomodensitométrie (computed tomography, CT) ou de l'imagerie par résonnance magnétique (IRM). Actuellement, l'imagerie nucléaire fonctionnelle par tomographie par émission de positons (positron emission tomography, PET) qui peut être couplée au CT (PET/CT) est de plus en plus appliquée aux patients présentant une tumeur maligne. Son efficacité a fréquemment été démontrée.

Le but de la présente étude est d'évaluer la valeur du PET dans la planification de la résection des tumeurs de la paroi thoracique. Une analyse rétrospective de dix-huit patients opérés entre 2004 et 2006 a été réalisée. Dans ce groupe de patient, la taille de la tumeur mesurée sur la pièce opératoire réséquée a été comparée à la taille de la tumeur mesurée sur le CT et le PET. Les résultats démontrent que le CT surestimait de manière consistante la taille réelle de la tumeur par rapport au PET (+64\% par rapport à $+1 \%, \mathrm{P}<0.001)$. De plus, le PET s'est avéré particulièrement performant pour prédire la taille des tumeurs de plus de $5.5 \mathrm{~cm}$ de diamètre par rapport au CT (valeur prédictive positive $80 \%$ par rapport à $44 \%$ et spécificité $93 \%$ par apport à 64\%, respectivement).

Cette étude démontre que le PET permettrait de mesurer la taille des tumeurs de la paroi thoracique de manière plus précise que le CT. Cette nouvelle modalité diagnostique s'avèrerait donc utile pour planifier les résections chirurgicales de telles tumeurs. A notre connaissance, aucune publication ne décrit la valeur du PET dans ce domaine. Les performances accrues du PET permettraient une meilleure délimitation des tumeurs ce qui améliorerait la précision de la résection chirurgicale.

En conclusion, cette étude préliminaire rétrospective démontre la faisabilité du PET pour les tumeurs de la paroi thoracique. Ces résultats devraient être confirmés par une étude prospective incluant un plus grand nombre de patients avec la perspective de juger l'impact clinique réel du PET sur la prise en charge thérapeutique des patients. 


\title{
Institutional report - Thoracic oncologic Value of positron emission tomography in full-thickness chest wall
resections for malignancies
}

\author{
David Petermann ${ }^{\mathrm{a}, *}$, Gilles Allenbach ${ }^{\mathrm{b}}$, Sabine Schmidtc, Igor Letovanec ${ }^{\mathrm{d}}$, Michel Christodoulou ${ }^{\mathrm{a}}$, \\ Angelika Bischof Delaloye ${ }^{\mathrm{b}}$, Hans-Beat Ris ${ }^{\mathrm{a}}$, John O. Prior ${ }^{\mathrm{b}, 1}$
}

aDivisions of Thoracic and Vascular Surgery, Centre Hospitalier Universitaire Vaudois (CHUV) and University of Lausanne, CH-1011 Lausanne, Switzerland 'Department of Nuclear Medicine, Centre Hospitalier Universitaire Vaudois (CHUV) and University of Lausanne, Lausanne, Switzerland cDepartment of Radiology, Centre Hospitalier Universitaire Vaudois (CHUV) and University of Lausanne, Lausanne, Switzerland 'Department of Pathology, Centre Hospitalier Universitaire Vaudois (CHUV) and University of Lausanne, Lausanne, Switzerland

Received 17 March 2009; received in revised form 13 May 2009; accepted 18 May 2009

\begin{abstract}
Preoperative imaging for resection of chest wall malignancies is generally performed by computed tomography (CT). We evaluated the role of ${ }^{18} \mathrm{~F}$-fluorodeoxyglucose (FDG) positron emission tomography (PET) in planning full-thickness chest wall resections for malignancies. We retrospectively included 18 consecutive patients operated from 2004 to 2006 at our institution. Tumor extent was measured by CT and PET, using the two largest perpendicular tumor extensions in the chest wall plane to compute the tumor surface assuming an elliptical shape. Imaging measurements were compared to histopathology assessment of tumor borders. CT assessment consistently overestimated the tumor size as compared to PET $(+64 \%$ vs. $+1 \%, P<0.001)$. Moreover, PET was significantly better than CT at defining the size of lesions $>24 \mathrm{~cm}^{2}$ corresponding to a mean diameter $>5.5 \mathrm{~cm}$ or an ellipse of $>4 \mathrm{~cm} \times 7.6 \mathrm{~cm}$ (positive predictive value $80 \%$ vs. $44 \%$ and specificity $93 \%$ vs. $64 \%$, respectively). Metabolic PET imaging was superior to CT for defining the extent of chest wall tumors, particularly for tumors with a diameter $>5.5 \mathrm{~cm}$. PET can complement CT in planning full-thickness chest wall resection for malignancies, but its true value remains to be determined in larger, prospective studies.
\end{abstract}

(C) 2009 Published by European Association for Cardio-Thoracic Surgery. All rights reserved.

Keywords: Chest wall; Positron emission tomography; Computed tomography; Cancer

\section{Introduction}

Full-thickness chest wall resection is a well-established technique that can be performed with acceptable morbidity and mortality. Careful preoperative assessment of the extent of the disease is necessary to achieve a radical resection in healthy tissues leading to optimal local control of the disease $[1,2]$. The size of the chest wall defect is related to postoperative complications and morbidity due to impaired respiratory function and mechanics of the chest [3]. Therefore, the accuracy of preoperative determination of the extent of resection is crucial to achieve a complete resection without excessive morbidity. This is particularly important for large tumors that require extensive and sometimes complex resections [4].

Classically, preoperative radiological assessment of the extent of chest wall malignancies is performed with contrast-enhanced computed tomography (CT) or magnetic

\footnotetext{
is $P$ resented at the 15th European Conference on General Thoracic Surgery, Leuven, Belgium, June 3-6, 2007.

John O. Prior is the recipient of an Academic Research Award from the Leenaards Foundation (Lausanne, Switzerland).

${ }^{*}$ Corresponding author. Tel.: +41213142045 (business) $/+417961361$ 29 (home); fax: +41213142358.

E-mail address: david.petermann@bluewin.ch (D. Petermann).

(c) 2009 Published by European Association for Cardio-Thoracic Surgery
}

resonance imaging $(M R I)[5,6]$. Positron emission tomography (PET) and its integration with $C T$ imaging (PET/CT) is nowadays frequently applied to the staging, re-staging and follow-up of patients with neoplasms [7]. The role of PET in planning full-thickness chest wall resection has never been analyzed. The purpose of this retrospective study was to evaluate the ability of PET in estimating tumor size of chest wall malignancies compared to classical morphological CT imaging.

\section{Materials and methods}

\subsection{Patient selection criteria}

We retrospectively evaluated consecutive patients who had full-thickness chest wall resection for malignancies performed at our institution from 2004 to 2006. After review of medical records, 18 patients had preoperative CT and PET imaging and were included (11 female and 7 male patients, mean age $60 \pm 9$ years, range 37-76). Resection indications were breast cancer recurrence $(n=10)$, chest wall metastasis $(n=6)$, primary chest wall sarcoma $(n=1)$ and desmoid tumor $(n=1)$. Our Institutional Ethics Committee approved this study and patient written consent was waived due to its retrospective nature. 


\subsection{Pathology}

Directly after full-thickness chest wall resection, each surgical specimen was oriented spatially and sent to the pathology unit. Macroscopic and microscopic examinations were performed by one pathologist. Tumor localization was appreciated and the size of the tumor in the chest wall plane by approximating the shape of the tumor by an ellipse. Its two greatest perpendicular axes, defined as the a-axis and the b-axis, were measured. This 2-dimensional measurement method was chosen to reflect the area of chest wall resected in the operating room. As full-thickness resection was always performed, the depth of the tumor across the chest wall had no impact. The tumor relation to the resection margins was also examined. The tumor size derived from the surgical specimen served as the standard of reference used for comparison with tumor size obtained on PET and CT imaging.

\section{3. $C T$}

Morphological cross-sectional imaging was performed using an 8- or 16- multidetector CT unit (GE Medical Systems, Milwaukee, Wisconsin). After intravenous (IV) iodinated contrast medium injection (Accupaque ${ }^{\circledR}$, lohexol, Amersham Health AG, Waedenswil, Switzerland) axial slices in arterial phase were performed covering the region from the cervicothoracic inlet to the diaphragm $(120 \mathrm{kV}$, $120 \mathrm{mAs}$, pitch 1.75, slice reconstruction $2.5 \mathrm{~mm} / 2 \mathrm{~mm}$ ). Two radiologists blinded to the PET and pathological findings analyzed the $\mathrm{CT}$ images in consensus using multiplanar image reconstruction of the axial CT slices (Advantage Workstation, GEMS, Milwaukee) using the same definition for tumor size measurement on pathology (Figs. 1 and 2). $\mathrm{CT}$ examinations were performed a median of 23 days

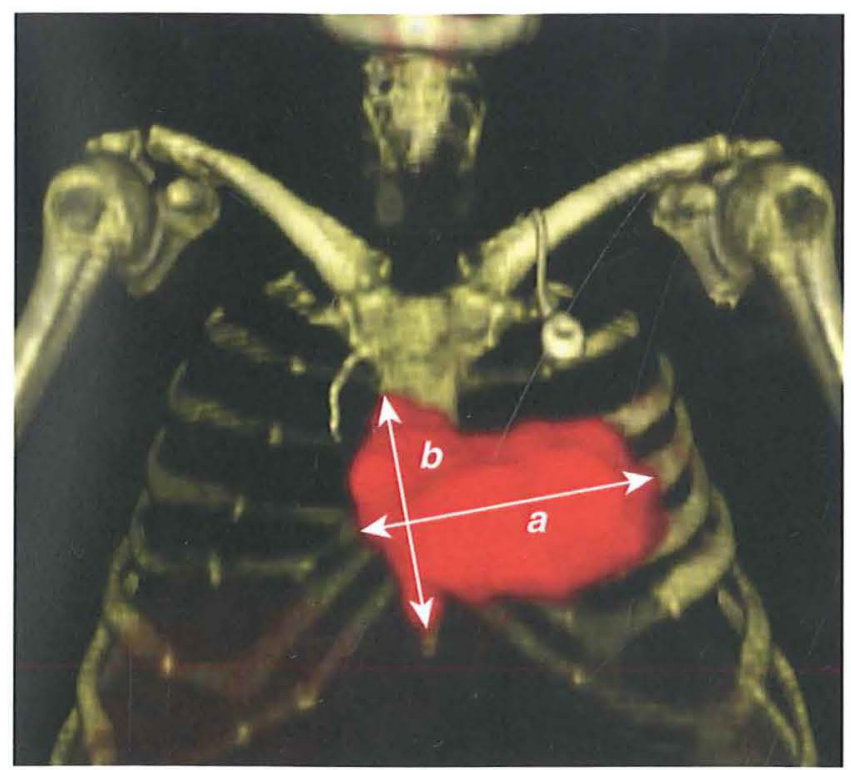

Fig. 1. Method used for tumor size measurement. PET/CT 3-D reconstruction of a tumor localized in the sternum and the left anterior part of the chest wall (red). The two perpendicular greatest tumor extensions ( $a$ and $b$ ) were measured similarly on CT imaging and in histopathological assessment.

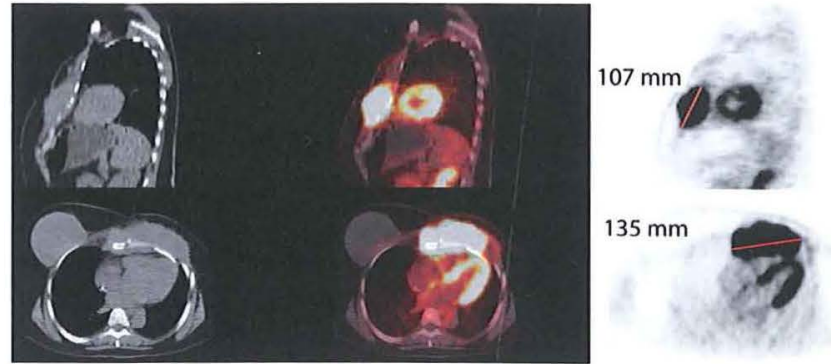

Fig. 2. PET measurements in a 55 -year-old woman with chest wall invasion by a breast cancer recurrence $\left(13.5 \mathrm{~cm} \times 10.7 \mathrm{~cm}\right.$, surface $\left.=113 \mathrm{~cm}^{2}\right)$.

before the operation [interquartile range $(I Q R)=25$ th -75 th percentile range $=2-41$ days).

\subsection{PET}

Eleven patients were studied using a hybrid PET/CT system without contrast enhancement (Discovery LS, GEMS, Milwaukee) and seven patients were studied using a PET only system (Advance NXi, GEMS, Milwaukee). In PET/ CT studies, the unenhanced CT was only used for attenuation correction and not for $\mathrm{CT}$ measurements. Patients were instructed to fast $>6 \mathrm{~h}$ before the injection of $5 \mathrm{MBq} /$ $\mathrm{kg}$ of ${ }^{18} \mathrm{~F}$-fluorodeoxyglucose (FDG). Two nuclear medicine physicians blinded to the CT and pathological findings analyzed PET only images in consensus with knowledge of clinical history and previous radiological imaging study results. Multiplanar image reconstructions were used for image interpretation (Advantage Workstation, GEMS, Milwaukee). On PET images, an increase in FDG uptake above a standardized uptake value (SUV) of $2.0 \mathrm{~g} / \mathrm{ml}$ was used to define malignancy. The tumor size was measured on PET images by defining its two greatest perpendicular extensions in the chest wall plane, with the same method as used by the pathologist (Figs. 1 and 2). PET examinations were performed a median of 31 (IQR 13-34) days before the operation.

\subsection{Surface calculation and statistical analysis}

Bidimensional calculation of tumor surface was performed considering the tumor as an ellipse in the chest wall plane (surface of an ellipse $S=\pi[a / 2] \cdot[b / 2]=\pi / 4 \cdot a \cdot b$ ). Statistical analyses were performed using Stata 10.0 software (College Station, Texas) using non-parametric Wilcoxon-test, Lin's concordance correlation (a measure of both precision and accuracy [8]), and robust linear regression analysis to compare the tumor size measurements of the surgical specimen with the values obtained with PET and CT. Twotailed hypothesis testing was used. Robust multivariate analysis was performed to determine how well each imaging modality would predict the tumor surface.

To investigate the possible clinical impact of PET in the planning of full-thickness chest wall resection, we assumed that more accurate determination of the tumor extent would be significant only for larger lesions. Indeed, for small resections, a more accurate determination of tumor extent by PET would not necessarily lead to a significantly 
different surgical excision than the one determined by CT. On the contrary, larger lesions would incur more extended surgery likely to include chest wall reconstruction and may benefit from the increased accuracy brought by PET. The optimal threshold was defined as the tumor surface measured on PET with the highest accuracy of PET to detect histopathology tumor extent. We determined the ability of each modality to determine if the tumor surface would be above this given threshold using receiver operating characteristics (ROC) curves and areas under the curve (AUC), and computing the corresponding sensitivity, specificity and accuracy with standard formulas.

\section{Results}

The mean size of the chest wall defect after resection (measured on the surgical specimen) was $128 \pm 94 \mathrm{~cm}^{2}$ (range $25-424 \mathrm{~cm}^{2}$ ). Complete resection (R0) was achieved in 15 patients $(83 \%)$ and 3 patients $(17 \%)$ presented microscopic infiltration (R1) of surgical margins (soft tissue infiltration in two patients and bony infiltration in one patient). The mean tumor surface measured by the pathologist on the surgical specimen was $40 \pm 67 \mathrm{~cm}^{2}$ (range $1-265 \mathrm{~cm}^{2}$ ), corresponding to a mean diameter of $7 \mathrm{~cm}$ or an ellipse of $6 \times 8.5 \mathrm{~cm}$ (Table 1 ).

\subsection{Comparison of PET and CT to predict tumor extent}

Classical morphological cross-sectional imaging significantly overestimated true tumor surface by $16 \pm 35 \mathrm{~cm}^{2}$ as compared to pathological measurements $(P=0.043)$. On the contrary, PET measurements overestimated tumor surface by $9 \pm 24 \mathrm{~cm}^{2}$ as compared to pathological findings, but the difference was not significant $(P=0.23)$. Fig. 3 shows the Bland-Altman plots with the corresponding limits of agreement. Using robust linear regression, CT tended to significantly overestimate the tumor size by $64 \%[95 \%$ confidence interval $(\mathrm{Cl})+44$ to $+90 \%$ ] in average, while
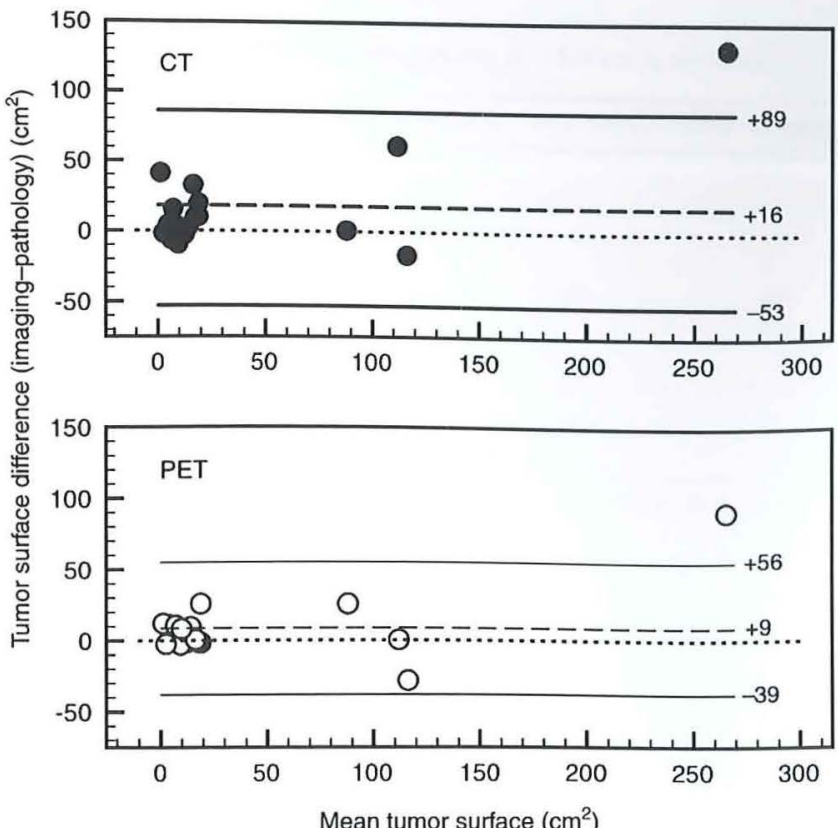

Fig. 3. Bland-Altman plots showing the difference vs. mean for each meas urement pairs. Upper panel, CT measured surface vs. pathology surface. The mean difference of $+16 \mathrm{~cm}^{2}$ (dashed line) was significantly different from 0 $(P=0.043)$. Lower panel, PET measured surface vs. pathology surface, with a mean difference of $+9 \mathrm{~cm}^{2}$ (dashed line), not significantly different from $0(P=0.23)$. Note the narrower $95 \%$ limits of agreement interval for PET as compared to CT (solid lines).

PET was almost equal to histopathological size with a $+1 \%$ ( $95 \% \mathrm{Cl}-13 \%$ to $+18 \%$ ) overestimation in average (Fig. 4 ). The concordance correlation coefficients between histopathological tumor surface and CT $\left(\rho_{\mathrm{c}}=0.89,95 \% \mathrm{Cl} 0.83-\right.$ $0.96)$ or PET $\left(\rho_{c}=0.95,95 \% \mathrm{Cl} 0.91-0.98\right)$ were excellent, with slightly higher values for PET, although the difference was not significant. In multivariate robust linear regression, PET was a better predictor of tumor extension measured

Table 1

Tumor histology and surface measured on pathology, CT and PET

\begin{tabular}{|c|c|c|c|c|c|c|}
\hline \multirow[t]{2}{*}{$n$} & \multirow{2}{*}{$\begin{array}{l}\text { Age } \\
\text { (years) }\end{array}$} & \multirow[t]{2}{*}{ Sex } & \multirow[t]{2}{*}{ Histology type } & \multicolumn{3}{|c|}{ Surface measurement $\left(\mathrm{cm}^{2}\right)$} \\
\hline & & & & Pathology & PET & $\mathrm{CT}$ \\
\hline 1 & 55 & $\mathrm{~F}$ & Breast carcinoma & 88.0 & 113 & 88.7 \\
\hline 2 & 60 & $\mathrm{~F}$ & Breast carcinoma & 4.91 & 4.10 & 532.7 \\
\hline 3 & 56 & $\mathrm{~F}$ & Breast carcinoma & 6.16 & 5.72 & $0.00^{*}$ \\
\hline 4 & 51 & $\mathrm{~F}$ & Breast carcinoma & 14.1 & 23.6 & 17.0 \\
\hline 5 & 65 & $\mathrm{~F}$ & Breast carcinoma & 1.18 & 13.2 & 42.4 \\
\hline 6 & 64 & $\mathrm{~F}$ & Breast carcinoma & 17.3 & 16.3 & 27.3 \\
\hline 7 & 65 & $\mathrm{~F}$ & Breast carcinoma & 18.9 & 44.6 & 38.5 \\
\hline 8 & 56 & $\mathrm{~F}$ & Breast carcinoma & 16.5 & 17.1 & 49.3 \\
\hline 9 & 66 & $\mathrm{~F}$ & Breast carcinoma & 7.07 & 17.7 & 22.6 \\
\hline 10 & 62 & $\mathrm{~F}$ & Breast carcinoma & 2.51 & $0.00^{*}$ & 0.88 \\
\hline 11 & 72 & $M$ & Thyroid carcinoma metastasis & 18.9 & 17.2 & 28.9 \\
\hline 12 & 63 & $M$ & Thyroid carcinoma metastasis & 12.4 & 11.1 & 9.80 \\
\hline 13 & 66 & M & Parotid adenocarcinoma metastasis & 9.35 & 6.41 & $0.00^{*}$ \\
\hline 14 & 76 & $M$ & Renal cell carcinoma metastasis & 116 & 88.0 & 99.8 \\
\hline 15 & 68 & M & Esophageal adenocarcinoma metastasis & 9.82 & 18.0 & 12.5 \\
\hline 16 & 37 & M & Mediastinal teratoma metastasis & 4.67 & 15.4 & 9.03 \\
\hline 17 & 53 & M & Desmoid tumor & 265 & 356 & 398 \\
\hline 18 & 49 & $\mathrm{~F}$ & Chondrosarcoma & 112 & 112 & 174 \\
\hline
\end{tabular}

*The tumor was not seen by this modality, but clinical recurrence was suspected.

$\mathrm{CT}$, computed tomography; PET, positron emission tomography; $\mathrm{F}$, female; $M$, male. 


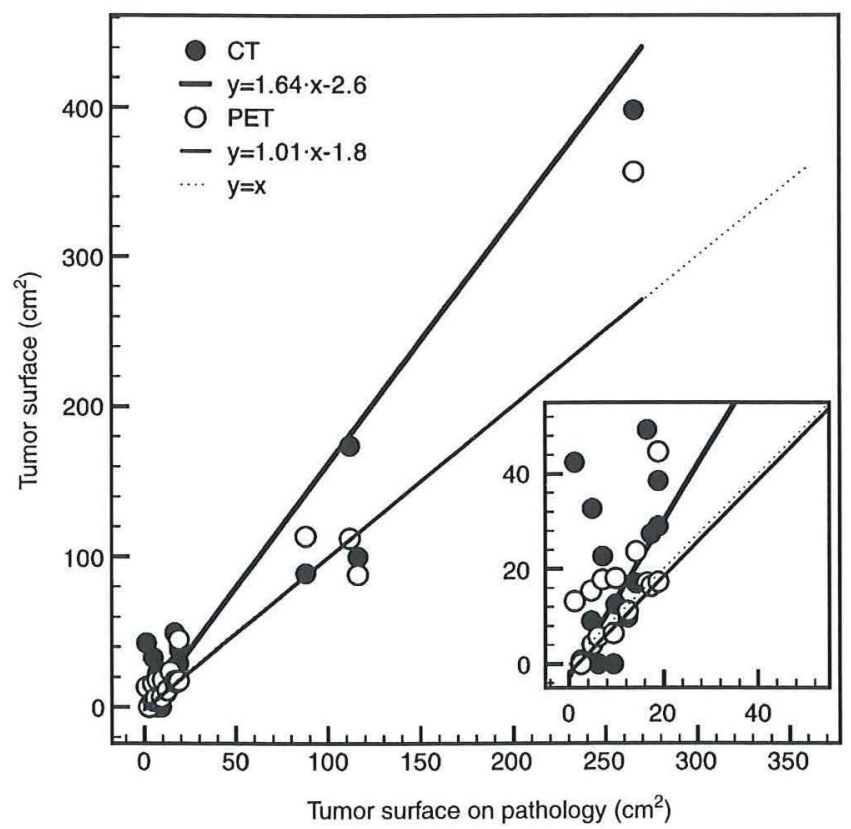

Fig. 4. Linear regression analysis of tumor surface on imaging vs. histopathology. CT overestimates tumor surface by $+64 \%$ (slope 1.64 , thick solid line), which was significantly more than when assessed by PET $(+1 \%$, slope 1.01 , thin solid line) almost no different from the identity line (dotted line).

on the pathological specimen $(\beta=0.61, P<0.001)$ than $\mathrm{CT}$ ( $\beta=0.23, P=0.042)$, while the difference was not significant $(P=0.13)$, however.

\subsection{Clinical impact of PET}

The optimal threshold with the highest accuracy of PET to detect histopathology tumor extent was found to be about $24 \mathrm{~cm}^{2}$, equivalent to a diameter of $5.5 \mathrm{~cm}$ or an ellipse of $4 \times 7.6 \mathrm{~cm}$. At this threshold, PET accuracy was maximized to reach $94 \%$. The corresponding positive and negative predictive values, sensitivity and specificity, and likelihood ratios for PET and CT to predict a tumor diameter of $>5.5 \mathrm{~cm}$ are given in Table 2. PET was significantly better than $\mathrm{CT}$ to determine the need for resection $>5.5 \mathrm{~cm}$, with a significantly better positive predictive value ( $80 \%$ vs. $44.4 \%$ ), specificity and AUC on ROC analysis (Fig. 5).

\section{Discussion}

Full-thickness resection of chest wall malignancies is currently performed in thoracic surgery units. Rewarding results can be obtained with acceptable morbidity even in the case of extended resections by use of synthetic substitutes and of pediculized myocutaneous flaps [3, 4, 9-12]. The cornerstone for long-term disease-free survival is a complete resection and preoperative planning of the extent of resection is usually performed by $\mathrm{CT}$ or MRI. In this retrospective study, we showed that PET-based measurements of tumoral extent better correlated with histopathological results than contrast-enhanced CT. In addition, PET allowed a significantly better prediction of histopathological results for large tumors $>5.5 \mathrm{~cm}$ in diameter as compared to enhanced CT. Thus, PET may be helpful in
Table 2

Ability of CT and PET for delineating lesions of $>5.5 \mathrm{~cm}$ in diameter

\begin{tabular}{llll}
\hline & CT measurement & PET measurement & $P$-value \\
\hline True positive & 4 & 4 & - \\
True negative & 9 & 13 & - \\
False positive & 5 & 1 & - \\
False negative & 0 & 0 & - \\
Sensitivity & $100 \%$ & $100 \%$ & $\mathrm{NS}$ \\
Specificity & $64 \%$ & $93 \%$ & 0.011 \\
Accuracy & $72 \%$ & $94 \%$ & $<0.001$ \\
Positive predictive value & $44 \%$ & $80 \%$ & $<0.001$ \\
Negative predictive value & $100 \%$ & $100 \%$ & $\mathrm{NS}$ \\
AUC (ROC analysis) & 0.82 & 0.96 & 0.026 \\
\hline
\end{tabular}

NS, not significant $(P>0.05)$; AUC, area under the curve; ROC, receiver operating characteristics.

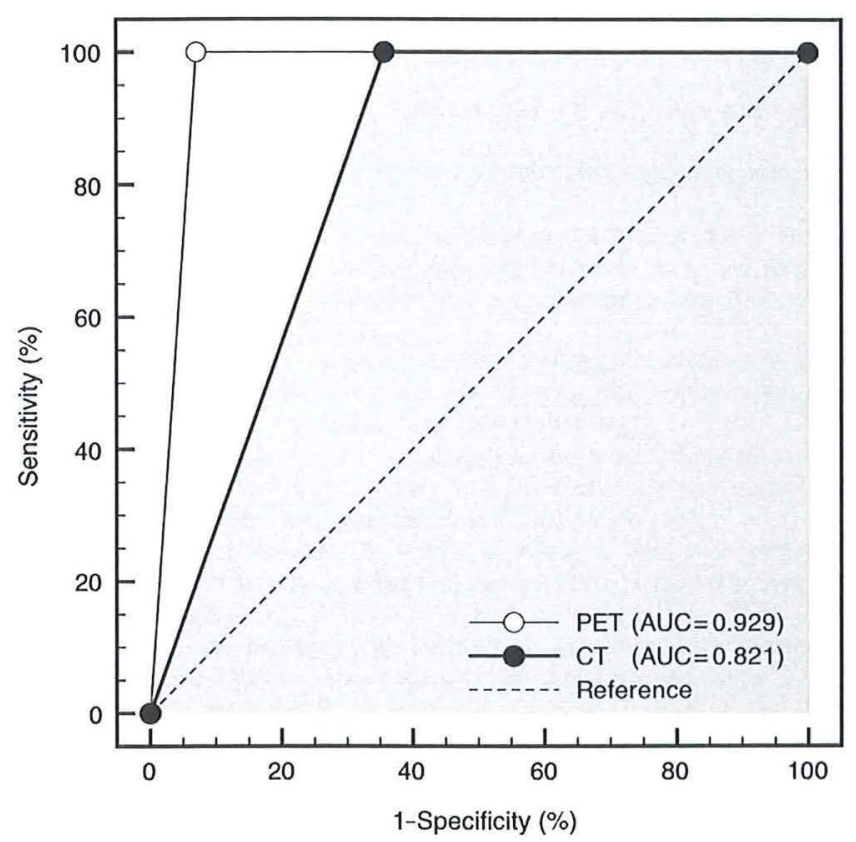

Fig. 5. Receiver operating characteristics (ROC) curves for CT (shaded area) and PET to predict resections of $>5.5 \mathrm{~cm}$ in diameter using histopathology as gold standard (dashed line $=$ reference line). The area under the curve (AUC) was significantly higher for PET as compared to CT $(P=0.026)$.

complementing imaging for the planning of full-thickness chest wall resection for malignant disease.

$\mathrm{PET} / \mathrm{CT}$ imaging is routinely used in modern oncological patient care, allowing a more accurate staging of tumor than morphological cross-sectional imaging. PET/CT enables in one examination to assess the local tumor extension and the detection of distant metastasis. The utility of PET has been described in evaluating chest wall involvement of lung cancer [13], but its use in planning chest wall resection has not been reported. Similarly, several studies have described the utility of PET/CT for diagnosing breast cancer recurrence. For instance, Radan et al. reported that PET/ $\mathrm{CT}$ was superior to $\mathrm{CT}$ for the diagnosis of recurrence and the assessment of the extent of the disease [14]. Interestingly, Briccoli et al. have reported the superiority of ultrasonography to CT and MRI in determining soft tissue resection margins of malignant chest wall tumors [15]. In their series of 22 patients, the authors obtained $100 \%$ of 
complete resection and showed that ultrasonography was particularly useful in identifying micronodules, but this technique is not applicable for the examination of the chest wall per se. MRI is frequently performed for investigation of tumors, particularly for osseous tumors. In our institution, MRI is rarely performed for chest wall malignancies because of the high quality of modern multidetector CT and the use of PET for local and distant staging of tumors. The role of MRI in this setting would need to be explored prospectively.

A limitation of our study would be the variety of histological types of the chest wall tumors, which may have had very different metabolic behaviors on PET. However, this heterogeneity reflects the daily clinical care of patients with chest wall tumors undergoing resection and reconstruction. Another limitation would be the retrospective design of our study. Thus, our promising results demonstrated the value of PET imaging for planning the extent of fullthickness resection for chest wall tumors. This would need to be confirmed in a larger, prospective study, where the PET information would be systematically integrated in resection planning. Such a study would allow in addition to determine the impact of PET on RO, as well as on the longterm outcome such as overall survival and recurrence rate.

In conclusion, our initial retrospective study suggests that PET might more accurately predict the extension of chest wall tumors than $\mathrm{CT}$ and would have a clinical impact in predicting the extent of required resections, especially in large tumors ( $>5.5 \mathrm{~cm}$ in diameter). However, prospective studies are needed to confirm these preliminary results and to determine the impact of delineating chest wall tumors by adding PET-derived information on tumor biology.

\section{Acknowledgments}

The authors are acknowledging the contribution of the physicians involved in the management of the patients, and M. Martins-Favre, MD (Department of Radiology, CHUV) for her contribution, as well as M. Faouzi, PhD (Institute of Social and Preventive Medicine, CHUV) for statistical review.

\section{References}

[1] Incarbone $M$, Pastorino U. Surgical treatment of chest wall tumors. World J Surg 2001;25:218-230.

[2] Mansour KA, Thourani VH, Losken A, Reeves JG, Miller JI Jr, Carlson GW, Jones GE. Chest wall resections and reconstruction: a 25-year experience. Ann Thorac Surg 2002;73:1720-1725; discussion 1725-1726.

[3] Weyant MJ, Bains MS, Venkatraman E, Downey RJ, Park BJ, Flores RM, Rizk N, Rusch VW. Results of chest wall resection and reconstruction with and without rigid prosthesis. Ann Thorac Surg 2006;81:279-285.

[4] Novoa N, Benito P, Jimenez MF, de Juan A, Luis Aranda J, Varela G. Reconstruction of chest wall defects after resection of large neoplasms: ten-year experience. Interact CardioVasc Thorac Surg 2005;4:250-255.

[5] Jeung MY, Gangi A, Gasser B, Vasilescu C, Massard G, Wihlm JM, Roy C. Imaging of chest wall disorders. Radiographics 1999;19:617-637.

[6] Tateishi U, Gladish GW, Kusumoto M, Hasegawa T, Yokoyama R, Tsuchiya $R$, Moriyama N. Chest wall tumors: radiologic findings and pathologic correlation: part 2. Malignant tumors. Radiographics 2003;23:14911508.

[7] Blodgett TM, Meltzer CC, Townsend DW. PET/CT: form and function. Radiology 2007;242:360-385.

[8] Lin LI. A concordance correlation coefficient to evaluate reproducibility. Biometrics 1989;45:255-268.

[9] Athanassiadi K, Kalavrouziotis G, Rondogianni D, Loutsidis A, Hatzimichalis A, Bellenis I. Primary chest wall tumors: early and long-term results of surgical treatment. Eur J Cardiothorac Surg 2001;19:589593.

[10] Lardinois D, Muller M, Furrer M, Banic A, Gugger M, Krueger T, Ris HB. Functional assessment of chest wall integrity after methylmethacrylate reconstruction. Ann Thorac Surg 2000;69:919-923.

[11] Veronesi G, Scanagatta P, Goldhirsch A, Rietjens M, Colleoni M, Pelosi $G$, Spaggiari L. Results of chest wall resection for recurrent or locally advanced breast malignancies. Breast 2007;16:297-302.

[12] Warzelhan J, Stoelben E, Imdahl A, Hasse J. Results in surgery for primary and metastatic chest wall tumors. Eur J Cardiothorac Surg 2001; 19:584-588

[13] Erasmus JJ, McAdams HP, Patz EF Jr, Goodman PC, Coleman RE. Thoracic FDG PET: state of the art. Radiographics 1998;18:5-20.

[14] Radan L, Ben-Haim S, Bar-Shalom R, Guralnik L, Israel O. The role of FDG-PET/CT in suspected recurrence of breast cancer. Cancer 2006; 107:2545-2551.

[15] Briccoli A, Galletti S, Salone M, Morganti A, Pelotti P, Rocca M. Ultrasonography is superior to computed tomography and magnetic resonance imaging in determining superficial resection margins of malignant chest wall tumors. J Ultrasound Med 2007;26:157-162. 